\title{
Introduction and Overview
}

\author{
Solomon Asfaw and Giacomo Branca
}

\begin{abstract}
The climate-smart agriculture (CSA) concept is gaining considerable traction at international and national levels to meet the challenges of addressing agricultural planning under climate change. CSA is a concept that calls for integration of the need for adaptation and the possibility of mitigation in agricultural growth strategies to support food security. Several countries around the world have expressed intent to adopt CSA approach to managing their agricultural sectors. However there is considerable confusion about what the CSA concept and approach actually involve, and wide variation in how the term is used. It is critical to build a more formal basis for the CSA concept and methodology and at the same time providing illustrations of how the concept can be applied across a range of conditions. This book expand and formalize the conceptual foundations of CSA drawing upon theory and concepts from agricultural development, institutional and resource economics. The book is also devoted to a set of country level case studies illustrating the economic basis of CSA in terms of reducing vulnerability, increasing adaptive capacity and ex-post risk coping. It also addresses policy issues related to climate change focusing on the implications of the empirical findings for devising effective strategies and policies to support resilience and the implications for agriculture and climate change policy at national, regional and international levels. The book provide development agencies and practitioners, policymakers, civil society, research and academia as well as private sector with tested good practices and innovative approaches of promoting CSA system at country level.
\end{abstract}

\footnotetext{
S. Asfaw $(\triangle)$

FAO of the UN, Rome, Italy

e-mail: Solomon.Asfaw@fao.org

G. Branca

Department of Economics, University of Tuscia, Viterbo, Italy

e-mail: branca@unitus.it
} 
Climate change poses a major and growing threat to global food security. Population growth and rising incomes in much of the developing world have pushed demand for food and other agricultural products to unprecedented levels. FAO has estimated that, in order to meet food demand in 2050, annual world production of crops and livestock will need to be $60 \%$ higher than it was in 2006. In developing countries, about $80 \%$ of the required increase will need to come from higher yields and increased cropping intensity and only $20 \%$ from expansion of arable land ${ }^{1}$.

Meeting food demand for a growing population is already a formidable challenge for the agriculture sector, but it will be further exacerbated by climate change. The expected effects of climate change - higher temperatures, extreme weather events, water shortages, rising sea levels, the disruption of ecosystems and the loss of biodiversity - will generate significant effects on the different dimensions and determinants of food security by affecting the productivity of rainfed crops and forage, reducing water availability and changing the severity and distribution of crop and livestock diseases. The fifth assessment report of the IPCC released in 2014 found that climate change effects are already being felt on agriculture and food security, and the negative impacts are most likely in tropical zones where most of the world's poor agricultural dependent populations are located. Through its impacts on agriculture, climate change will make it more difficult to meet the key Sustainable Development Goal of ending hunger, achieving year-round food security, and ensuring sustainable food production systems by 2030 .

The magnitude and speed of climate change, and the effectiveness of adaptation and mitigation efforts in agriculture, will be critical to the future of large segments of the world's population. Integrating the effects of climate change into agricultural development planning is a major challenge. This requires technology and policy measures to reduce vulnerability and increase the capacity of producers, particularly smallholders, to effectively adapt. At the same time, given agriculture's role as a major source of greenhouse gas emissions and the high rate of emissions growth experienced with recent conventional intensification strategies, there is a need to look for low emissions growth opportunities and adequate policies. Policymakers are thus challenged to ensure that agriculture contributes to addressing food security, development and climate change.

In this frame, Climate Smart Agriculture (CSA) is an approach that calls for integration of the need for adaptation and the possibility of mitigation in agricultural growth strategies to support food security. The concept was launched by FAO in $2010^{2}$, gaining rapid and widespread interest and attention. CSA goes beyond agricultural practices and technologies to include enabling policies and institutions as well as identification of financing mechanisms. There are significant intellectual and policy gaps to be filled in CSA literature. An economic decision-making framework will also assist in identifying challenges for CSA application.

\footnotetext{
${ }^{1}$ See http://www.fao.org/fileadmin/templates/wsfs/docs/expert_paper/How_to_Feed_the_World_ in_2050.pdf.

${ }^{2}$ See http://www.fao.org/docrep/013/i1881e/i1881e00.pdf.
} 


\section{Overview of the Book}

This book expands and formalizes the conceptual foundations of CSA drawing upon theory and concepts from agricultural development, institutional and resource economics. The book focuses particularly on the adaptation/resilience dimension of CSA, since this is the least well developed in the economics literature. A mixture of conceptual analyses, including theory, empirical and policy analysis, and case studies look at: (1) ex-ante reduction of vulnerability, (2) increasing adaptive capacity through policy response, (3) increasing adaptive capacity through system level response and (4) increasing adaptive capacity through farm level response.

The book provides a wide array of case studies to illustrate that these concepts have strong real-world applicability. The case study approach will provide concrete illustrations of the conceptual and theoretical framework, taking into account the high level of diversity in agro-ecological and socioeconomic situations faced by agricultural planners and policy-makers today. Some case studies assess issues of measurement of vulnerability to climate change and damage caused by it. Others address issues of improving adaptive capacity, and the ex-post impact of different policy measures.

In the book, economists and policy-makers will find an interpretation and operationalizing of the concepts of resilience and adaptive capacity in the context of agricultural growth for food security. The combination of methodological analysis of CSA and an empirical analysis based on a set of case studies from Asia and Africa is unique. We are not aware of other books that contain all of this integrated knowledge in one place and provide a perspective on its lessons.

The book is structured as follows. Part I illustrates the conceptual framework, giving an overview of CSA concept, approach, and its main components. This part relates the main features of the CSA paradigm to core economic principles and seeks to clarify how the concepts of resilience, adaptive capacity, innovation, technology adoption and institutions relate to each other and the economic principles of CSA. Part II reports a set of case studies from leading agricultural development economists aimed at illustrating the economic basis of CSA in terms of reducing vulnerability and increasing adaptive capacity. It makes a clear distinction between responses to building adaptive capacity at policy, system and farm levels. Last, part III addresses policy issues related to climate change and provides a synthesis of the key messages of the book. A detailed overview of each part is presented next.

\subsection{Part I. Conceptual Chapters}

Chapter 2 presents an overview of the evolution of CSA concept, introduces its major components, and summarizes the key issues associated within the context of climate change and agricultural policy debates. The main message of this chapter is that CSA concept has been reshaped through inputs and interactions of multiple 
stakeholders involved in developing and implementing it. The first section provides an overview of international climate change policy followed by an introduction and analysis of CSA and its history. This is then followed by a discussion of three broad controversies related to CSA, namely the role of mitigation, the relationship of CSA to sustainable agriculture, and how biotechnology is treated in the CSA approach. CSA provides a tool to identify locally appropriate solutions to managing agriculture for sustainable development and food security under climate change.

Chapter 3 tackles the economic considerations of CSA in addressing sustainable agricultural growth for food security under climate change. It addresses the lack of coherence of the CSA approach by building a conceptual framework to rooted in agricultural development economic theories and concepts. The chapter begins by highlighting the key features of climate change that require a shift in emphasis in research, and for innovations in technologies, institutions, and government policies and programs to consider heterogeneity of impacts and implications of decisionmaking under uncertainty. The chapter does this by posing a dynamic constrained optimization problem wherein a social planner seeks to maximize expected discounted welfare associated with agriculture of the population they serve, both now and in the future. The objectives are the four pillars of food security, food availability, accessibility, utilization, and stability, as well as reducing emissions growth. The problem is also characterized by current constraints that bound the feasible outcomes, including bio-physical, behavioral, political, institutional and distributional constraints. The chapter stresses that the nature of the optimization, and thus adaptation strategies, are context specific and highlight that the solution to the social planner's problem for climate change must balance adaptation and responsiveness to uncertain climate change with the needed growth and food security objectives of the agricultural sector.

Chapter 4 provides more detailed guidance on the key role of innovation to address the negative impact of climate change. Innovation in agriculture is clearly an important response for effective and equitable adaptation and mitigation - and the chapter highlights the need for managerial and institutional changes that promote innovation to address the heterogeneity and uncertainty of climate change impacts. The chapter discusses the main features and the nature of innovation needed to align these actions with a CSA strategy, suggesting several principles to guide the introduction of innovation and develop capacity and policies to address climate change.

\subsection{Part II. Country Case Studies}

\subsubsection{Vulnerability Measurement and Assessment}

Chapter 5 shows that near real-time satellite observations can be used to mitigate impacts of extreme events and promote climate resilience. First, the early detection of growing conditions and predicting the availability of food directly improves 
climate resilience and food security. Second, insurance (risk management) programs can use the indexes in triggers for a quick release of catastrophic bonds to farmers to mitigate impacts of crop failure. Third, these tools provide information useful for farmers in assessing yield potential from various crops under current and changing climatic conditions. Fourth, an early warning system distributed across the globe can help identify and expedite the exportation of food supplies from areas where they are in excess into areas where a deficiency is likely to occur. The chapter also discusses ways of integrating these products with various datasets, such as in situ surface temperature, the greenness index, and soil moisture data, in order to expand their complementary value and utility.

Chapter 6 presents key findings from advanced econometric models of long-term impacts of climate change on rice production in Lao PDR. Results are consistent with previous work in the region, where there is weak evidence that elevated minimum night-time temperatures are highly damaging to rice yields. Conversely, it is found that elevated maximum daytime temperatures increase yields. Overall, the size of the impact and statistical significance is larger for increased maximum temperatures, suggesting that elevated temperatures might have a net positive impact on rice yields in Lao PDR. The chapter also discusses some major caveats to these findings in particular the limitation with the quality data used for the analysis.

The perception of climate change and adaptation choices made by farmers are important considerations in the design of adaptation strategies. Chapter 7 uses a comprehensive dataset of farm households from Thailand and Vietnam to show that farmers do perceive climate change, but describe it in quite distinct ways. Further, adaptation measures are informed by perception and, at least in the case of Vietnam, perceptions are shaped by the respondent's characteristics, location variables and recent climate related shocks.

Chapter 8 illustrates how to assess the yield growth rate requirements needed to compensate yield losses due to climate change. The crop statistical model employed allows for nonlinear effects of temperature on yields. In line with the literature, it suggests that exposure to temperature exceeding $30{ }^{\circ} \mathrm{C}$ is detrimental to maize yields in the US Midwest. The chapter reports that a historical rate in maize yield growth in the US Midwest of $17.4 \%$ /decade exceeds the rate $(6.56 \%$ /decade $)$ needed to compensate a plausible warming of $3{ }^{\circ} \mathrm{C}$ within the next 3 decades. However, the net yield trend would be substantially diminished under this scenario due to the countervailing effect of a warming climate. The chapter also discusses the possibilities of extending the analysis with a cost-benefit analysis of alternative meanincreasing or variance-reducing technological change.

Chapter 9 shows that a fine-tuned integrative decision support tool can better inform growers and landowners of how changes in climate will impact their operations and their environmental outcomes. The use of a decision support tools such as AgBiz Logic can provide farmers better information on the relative impacts of adapting to a change as reflected in changes in future climate conditions, changes in future policies, prices, and costs or changes in terms of lease arrangements. By incorporating both climate change and environmental outcomes, these decision tools can be used to evaluate climate smart options at the farm-scale. The authors 
discuss the use of different tools such as AgBizClimate, AgBizProfit, AgBizFinance,

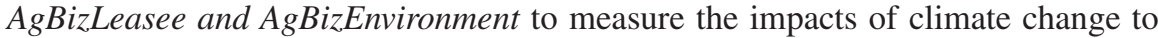
wheat production, the role of adaptation strategies to an annual cropping system, the feasibility of purchasing additional equipment to farm the annual cropping system and also estimate the trade-offs of economic returns to environmental impacts.

\subsubsection{Policy Response to Improving Adaptation and Adaptive Capacity}

Chapter 10 uses empirical evidence from the Index-based Livestock Insurance (IBLI) project in the pastoral regions in East Africa to answer if insurance can costeffectively mitigate the increasingly deleterious impacts of climate risk on poverty and food insecurity. The theory reviewed in this chapter suggests an affirmative answer if well-designed insurance contracts can be implemented and priced at a reasonable level despite the uncertainties that attend climate change. At the same time, much remains to be done if quality index insurance contracts are to be scaled up and sustained. Demand has often been tepid and unstable. Outreach and administration costs have been high. Pricing by a private insurance industry made nervous by climate change has pushed costs up. Finally, the effective quality of the IBLI contact has been scrutinized and found wanting. The chapter concludes that insurance is not an easy, off-the-shelf solution to the problem of climate risk and food insecurity. Creativity in the technical and institutional design of contracts is still required.

Chapter 11 synthesizes the key findings of From Protection to Production Project (PtoP) of FAO to show the potential role of cash transfer programmes as a tool to support risk management and build resilience in sub-Saharan Africa. Such programs address household resilience by building human capital and improving food security and potentially strengthening households' ability to respond to and cope with exogenous shocks. This may allow households to mitigate future fluctuations in consumption. Many of the programmes studied increased investment in agricultural inputs and assets, including farm implements and livestock, and improved food security indicators, though results differed across countries. This too was met by increases in consumption and dietary diversity. Although the impacts on risk management are less uniform, the cash transfer programmes seem to strengthen community ties, allow households to save and pay off debts, and decrease the need to rely on adverse risk coping mechanisms. Finally, using the case study of Zambia the authors demonstrates the potential for cash transfers to help poor households manage climate risk.

Chapter 12 shows that Input Subsidy Programs (ISPs) may provide a potentially useful means to encourage system-wide and farm-level changes to achieve CSA objectives in Africa. While many ISPs have not contributed significantly to ex-ante risk management at the household level, recent innovations in ISPs may enable them to be more climate smart. In particular, moves toward open voucher systems that induce greater private sector participation hold potential to support the development of profitable and more sustainable input distribution systems providing more heat-, drought- and saline-tolerant seed types. Moreover, moving 
from a limited range of options to a system that provides farmers with a wide range of input choices has the potential to promote greater livelihood diversification and resilience. Programs that make farmer participation in ISPs conditional on the adoption of certain climate smart practices also have some potential but would require more robust monitoring and setting of targets. These two requirements currently limit the potential of ISPs to achieve widespread CSA benefits. Moreover, using ISPs to contribute to CSA objectives would need to be evaluated against the potential benefits of using comparable resources for investments in irrigation, physical infrastructure, and public agricultural research and extension programs, which may generate higher comprehensive social benefits.

\subsubsection{System Level Response to Improving Adaptation and Adaptive Capacity}

The expansion of irrigation is often considered as a complementary strategy to enhance the resilience of agriculture to climate. However, irrigation entails large capital expenditures and an adequate sizing of any given irrigation scheme cannot neglect the expected changes in climate trends and variability. Chapter 13 explores these issues using historical climate records as a basis for determining what investment is adequate in water storage or in area equipped for irrigation is likely to result in "regrets," because the investment will be undersized/oversized, if the climate turns out to be drier/wetter than expected. An investment strategy that minimizes the risk of misjudgements across multiple climate outcomes reduces regrets and allows for greater flexibility of the system: cropping patterns, water use, or other parameters can be adapted for wet or dry years to increase the return on irrigation investment.

Chapter 14 shows how the use of the new simulation-based technology impact assessment methods, developed by the Agricultural Model Inter-comparison and Improvement project (AgMIP), can evaluate the potential for currently available or prospective agricultural systems to achieve the goals of CSA. The approach combines available data (observational and farm performance indicators), with bio-physical and economic models and future climate and socio-economic scenarios. A case study of crop-livestock systems in Zimbabwe illustrates the potential for these methods to test the usefulness of specific modifications to raise incomes, reduce vulnerability to climate change and to enhance resilience. It is important to note that the framework presented can also incorporate greenhouse gas emissions as part of a technology assessment. The authors point out the need to incorporate livestock herd dynamics and interaction of crop and livestock systems into the methodology.

Chapter 15 tackles four major issues with respect to food supply chain in the context of climate change. First, the importance of analysing climate short-term shocks and long-term change on the full food supply chain (inputs, farms, processing, and distribution). Second, the authors show the importance of viewing a given supply chain as an interdependent set of segments and sub-segments. 
Climate shocks upstream in the supply chain can disrupt a wide complex of midstream and downstream activities. Third, supply chain analysis is greatly benefited by using "hot spots" of vulnerability to understand climate impacts, both before and after the farm gate. Fourth, climate shocks, and strategies to mitigate them, can be viewed from as (i) strategic supply chain design choices by actors along the supply chain, of sourcing and marketing systems, geography, institutions, and organization; and (ii) threshold investments by actors (firms and farms) along all supply chains.

Chapter 16 uses a conceptual model and empirically-based simulations to investigate the effectiveness of extension-driven informational programs, rain-indexed crop insurance, and the interaction of the two programs in driving adaptation and providing a safety net for farmers. Based on options between diversification strategies and land management practices, different potential welfare outcomes for agricultural households are investigated. The findings show that CSA techniques, including advanced information, about changing conditions in Malawi can mitigate expected losses. The value of this information is greater for farmers with lessbinding subsistence constraints and under scenarios for which the effects of climate change are larger. Rain-indexed insurance appears to drive farmers to increase their usage of cash crops and higher yield/higher variability hybrid crop options. Such information is even more important in addressing larger expected losses among farmers with greater flexibility.

The mixed crop-livestock systems of the developing world will become increasingly important for meeting food security challenges of the coming decades. Chapter 17 addresses the gap in understanding of the synergies and trade-offs between food security, adaptation, and mitigation objectives based on a systematic review protocol coupled with a survey of experts. The chapter also discusses constraints to the uptake of different interventions and the potential for their adoption, and highlights some of the technical and policy implications of current knowledge and knowledge gaps.

The effectiveness of a policy depends on specific climate, demographic, environmental, economic and institutional factors. Chapter 18 introduces temporal aspects of household vulnerability to a conceptual model building on available econometric results. The method is based on a factorial design with two vulnerability levels and two production methods. Farms are classified into groups based on cluster analysis of survey data from Zambia. The chapter shows that small, vulnerable farms are more likely to face labor and cash constraints, which may prevent them from adopting technologies that have the potential to sustainably improve food security and enhance their adaptive capacity, i.e. be climate-smart. Widespread adoption, however, will require policies that address the barriers identified here to provide: (i) improved techniques that are less labor intensive, (ii) improved availability of fertilizers, and (iii) credit to cover the up-front costs of investing in soil health that takes several years to bear fruit. 


\subsubsection{Farm Level Response to Improving Adaptation and Adaptive Capacity}

Chapter 19 uses Mali and Nigeria as case study countries to show that sustainable land and water management (SLWM) could more than offset the effect of climate change on yield under the current management practices. Despite the benefits, adoption rates of SLWM remain low. The authors discuss policies and strategies for increasing their adoption including improvement of market access, enhancing the capacity of agricultural extension service providers to provide advisory services on SLWM, and building an effective carbon market that involves both domestic and international buyers.

Chapter 20 identifies the key barriers, opportunities and impacts for a wider adoption of climate smart technologies by differentiated groups of agricultural producers, with a focus on the poor in Central Asia. It is found that access to markets and extension, and higher commercialization of household agricultural output, may serve as major factors facilitating the adoption of CSA technologies. The adoption of CSA technologies has a positive impact on the farming profits of both poorer and richer households, although these positive impacts may likely to be higher for the richer households. Even still, adoption rates among the poorer households are lower than among the richer households.

Chapter 21 shows the implications of farm households' past decision to adapt to climate change on current downside risk exposure in the Nile Basin of Ethiopia. Using moment-based specification to capture the third moment of a stochastic production function as measure of downside yield uncertainty, it finds that past adaptation to climate change (i) reduces current downside risk exposure, and so the risk of crop failure; (ii) would have been more beneficial to the non-adopters if they had adopted, in terms of reduction in downside risk exposure; and (iii) is a successful risk management strategy for adopters.

Chapter 22 uses case studies from Zambia and Malawi to discuss the drivers of diversification and its impacts on selected welfare outcomes with a specific attention to climatic variables and institutions. Geo-referenced farm-household-level data merged with data on historical rainfall and temperature as well as with administrative data on relevant institutions are used to demonstrate that diversification is an adaptation response, as long term trends in climatic shocks have a significant effect on livelihood diversification, albeit with different implications. Access to extension agents positively and significantly correlates with diversification in both countries. The results also demonstrate that the risk-return trade-offs are not as pronounced as might be expected.

Chapter 23 presents a case study on potential impacts and implications for adoption of CSA solutions in the Northern Mountainous Region (NMR) of Viet Nam. The authors use primary data collected through ad hoc household and community surveys in the study area, on the costs and benefits of agricultural practices, as well as on socio-economic information relevant for households' adoption decisions. A profitability estimate and technology adoption analysis indicate that the potential of some sustainable farming practices to increase productivity and incomes and pro- 
vide adaptation benefits under the specific climate patterns being experienced in NMR of Viet Nam, particularly in "critical growing periods" of crops. However, such practices often have higher capital and labour requirements, which are likely to prevent or impede adoption. The findings suggest the importance of local climate and socio-economic contexts in determining which practices will actually be climate-smart. Results highlight the importance of using climate information for targeting the promotion of improved practices, and building adaptive capacity amongst farmers.

\subsection{Part III. Policy Synthesis and Conclusion}

Chapter 24 focuses on the implications of the empirical findings for devising effective strategies and policies to support resilience and the implications for agriculture and climate change policy at national, regional and international levels. This section is built upon the analysis provided in the case studies as well as short "think" pieces on specific aspects of the policy relevance issues from policy makers as well as leading experts in agricultural development and climate change. Lastly, Chapter 25 is a synthesis to identify and reconcile the common themes across all the chapters and draws some major economic conclusions and policy recommendations.

Open Access This chapter is distributed under the terms of the Creative Commons AttributionNonCommercial-ShareAlike 3.0 IGO license (https://creativecommons.org/licenses/by-nc-sa/3.0/ igo/), which permits any noncommercial use, duplication, adaptation, distribution, and reproduction in any medium or format, as long as you give appropriate credit to the Food and Agriculture Organization of the United Nations (FAO), provide a link to the Creative Commons license and indicate if changes were made. If you remix, transform, or build upon this book or a part thereof, you must distribute your contributions under the same license as the original. Any dispute related to the use of the works of the FAO that cannot be settled amicably shall be submitted to arbitration pursuant to the UNCITRAL rules. The use of the FAO's name for any purpose other than for attribution, and the use of the FAO's logo, shall be subject to a separate written license agreement between the FAO and the user and is not authorized as part of this CC-IGO license. Note that the link provided above includes additional terms and conditions of the license.

The images or other third party material in this chapter are included in the chapter's Creative Commons license, unless indicated otherwise in a credit line to the material. If material is not included in the chapter's Creative Commons license and your intended use is not permitted by statutory regulation or exceeds the permitted use, you will need to obtain permission directly from the copyright holder. 